
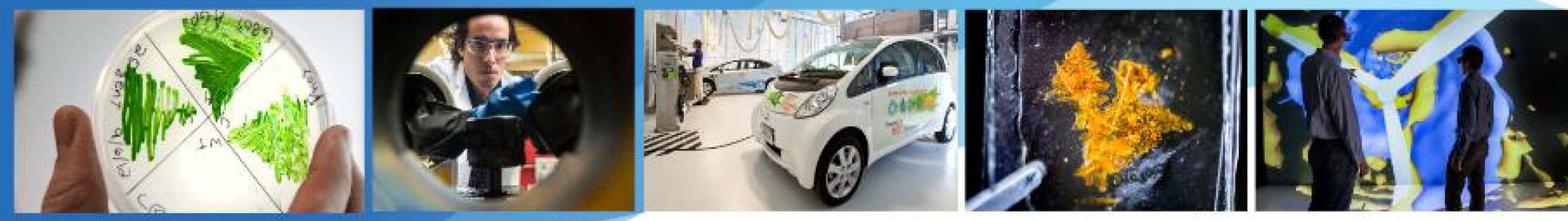

\section{An Analysis of Techno-Economic Requireme
for MOSAIC CPV Systems to Achieve Cost} Competitiveness

${ }^{1}$ Kelsey A. W. Horowitz, ${ }^{2}$ Daniel W. Cunningham, and

2James Zahler

OSA Light, Energy, and the Environment

Novmber 6, 2017

Boulder, Colorado

1) National Renewable Energy Laboratory, Golden $\mathrm{CO}$

2) Advanced Research Project Agency-Energy, 1000 Independence Ave., Washington DC 


\section{Analysis Disclaimer}

\section{DISCLAIMER AGREEMENT}

These manufacturing cost model results ("Data") are provided by the National Renewable Energy Laboratory ("NREL"), which is operated by the Alliance for Sustainable Energy LLC ("Alliance") for the U.S. Department of Energy (the "DOE").

It is recognized that disclosure of these Data is provided under the following conditions and warnings: (1) these Data have been prepared for reference purposes only; (2) these Data consist of forecasts, estimates or assumptions made on a best-efforts basis, based upon present expectations; and (3) these Data were prepared with existing information and are subject to change without notice.

The names DOE/NREL/ALLIANCE shall not be used in any representation, advertising, publicity or other manner whatsoever to endorse or promote any entity that adopts or uses these Data. DOE/NREL/ALLIANCE shall not provide any support, consulting, training or assistance of any kind with regard to the use of these Data or any updates, revisions or new versions of these Data.

YOU AGREE TO INDEMNIFY DOE/NREL/ALLIANCE, AND ITS AFFILIATES, OFFICERS, AGENTS, AND EMPLOYEES AGAINST ANY CLAIM OR DEMAND, INCLUDING REASONABLE ATTORNEYS' FEES, RELATED TO YOUR USE, RELIANCE, OR ADOPTION OF THESE DATA FOR ANY PURPOSE WHATSOEVER. THESE DATA ARE PROVIDED BY DOE/NREL/ALLIANCE "AS IS" AND ANY EXPRESS OR IMPLIED WARRANTIES, INCLUDING BUT NOT LIMITED TO, THE IMPLIED WARRANTIES OF MERCHANTABILITY AND FITNESS FOR A PARTICULAR PURPOSE ARE EXPRESSLY DISCLAIMED. IN NO EVENT SHALL DOE/NREL/ALLIANCE BE LIABLE FOR ANY SPECIAL, INDIRECT OR CONSEQUENTIAL DAMAGES OR ANY DAMAGES WHATSOEVER, INCLUDING BUT NOT LIMITED TO CLAIMS ASSOCIATED WITH THE LOSS OF DATA OR PROFITS, WHICH MAY RESULT FROM AN ACTION IN CONTRACT, NEGLIGENCE OR OTHER TORTIOUS CLAIM THAT ARISES OUT OF OR IN CONNECTION WITH THE USE OR PERFORMANCE OF THESE DATA. 


\section{Incumbent Flat Plate PV Technology}
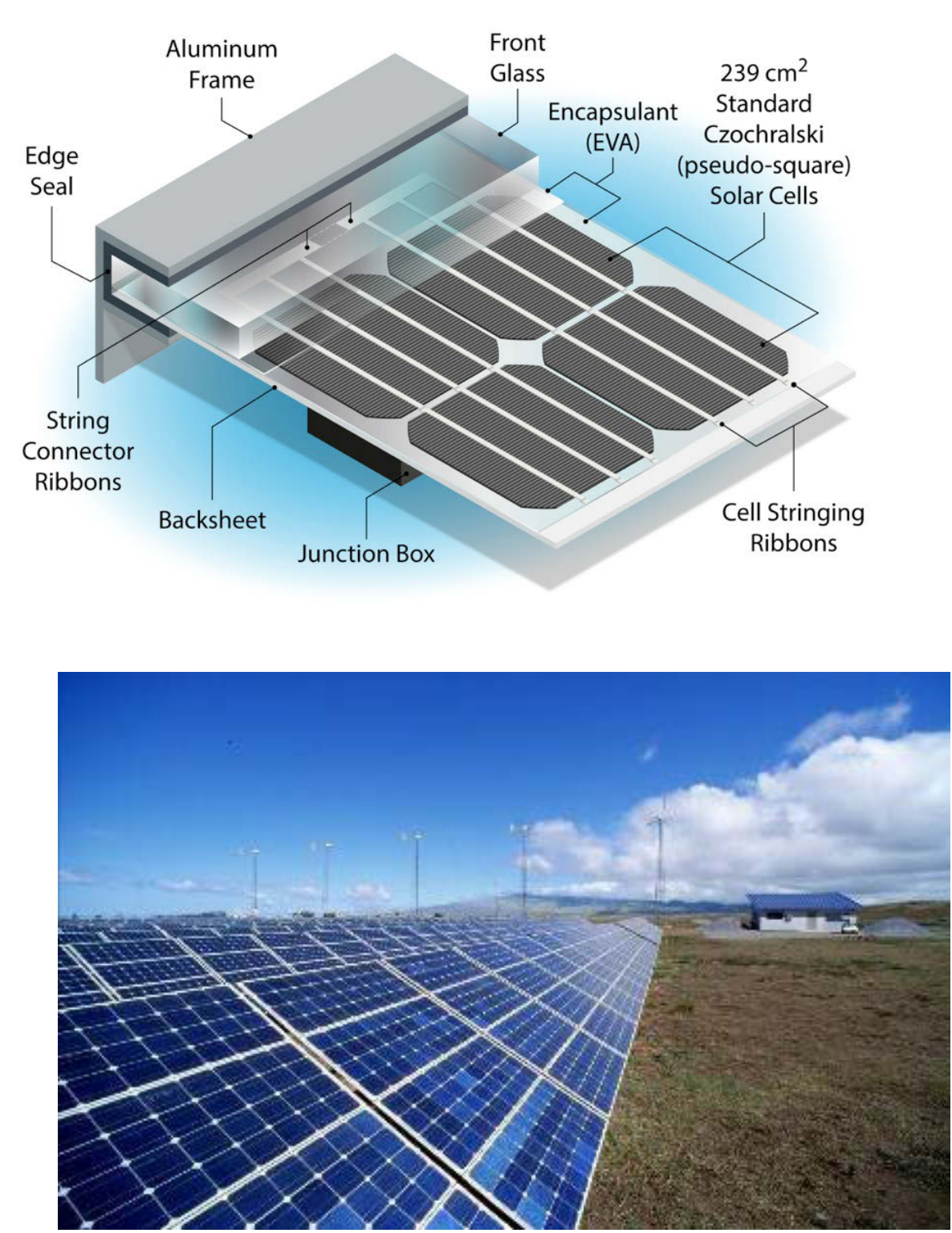

NATIONAL RENEWABLE ENERGY LABORATORY
- Flat-plate c-Si is $>90 \%$ of the PV market

- Module costs and prices have decreased rapidly and significantly - \$0.35/W ex-factory gate average price in 2017

- Single-junction devices have limits on efficiency

- Fixed-tilt systems suffer from cosine losses

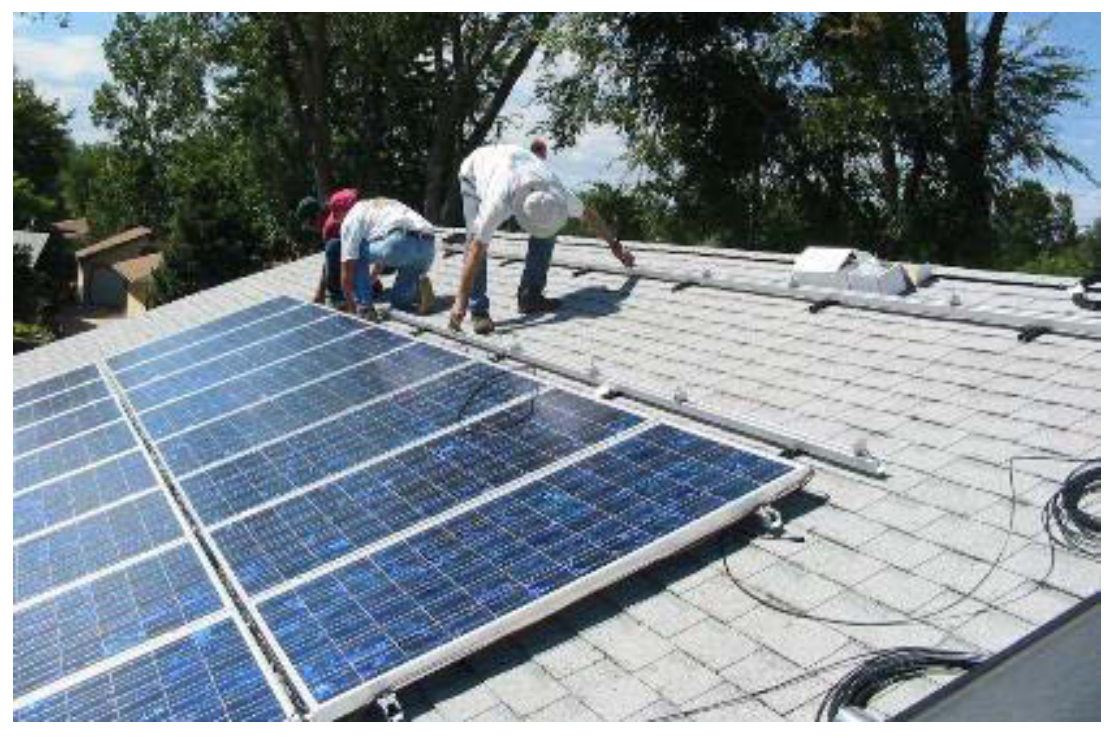




\section{CPV Concepts and the MOSAIC Program}

\section{Traditional HCPV Systems}

- Myriad of different designs

- Thicker than traditional flat plate modules

- Require accurate 2-axis tracking

- Cannot collect diffuse sunlight

\section{Micro-scale Optimized Solar cell Arrays with Integrated Concentration (MOSAIC)}

- Myriad of different designs

- Form factor similar to flat plate technology: Approx. $2.5 \mathrm{~cm}$ array height

- Either have relaxed tracking requirements or do not require external tracking

- Most able to collect some diffuse light
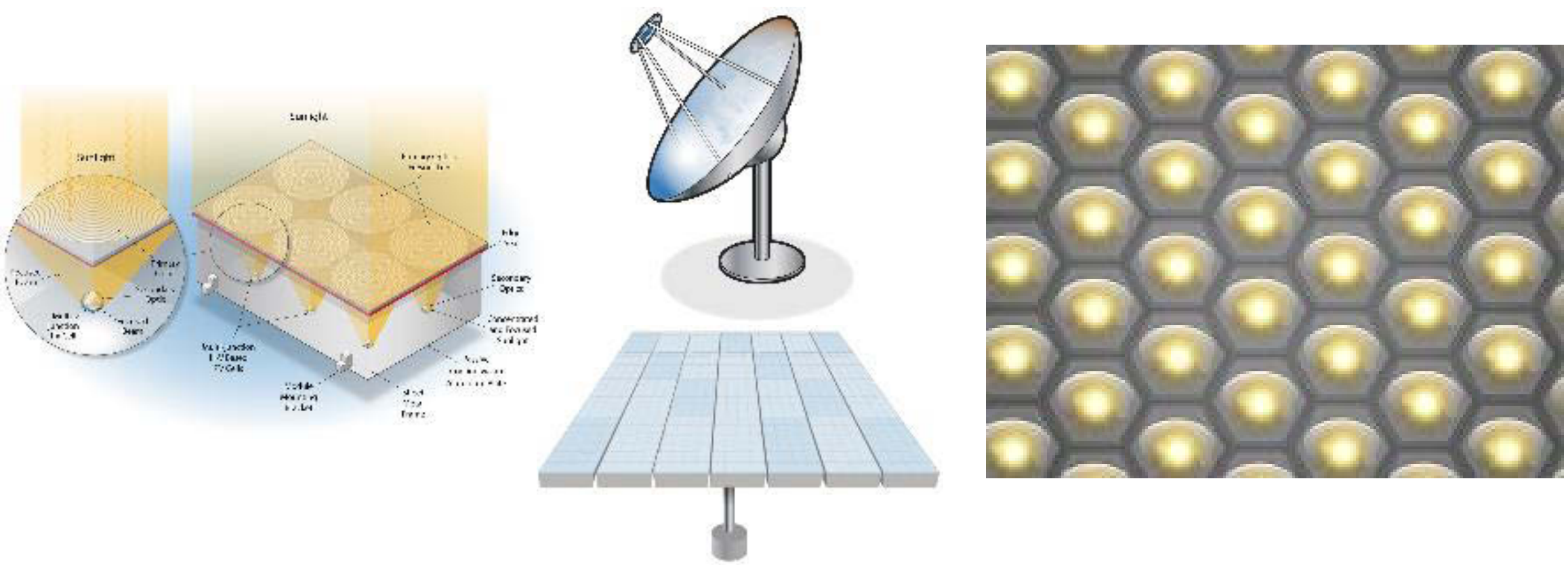


\section{Techno-Economic Analysis Overview}

- Conducted bottom-up cost analysis relevant to a range of MOSAIC designs, including fixed-tilt and tracked systems

- Built a new bottom-up, engineering cost model of a dual-axis tracker for modeling tracked MOSAIC designs

- Leveraged NREL's existing bottom-up system models of fixed-tilt rooftop and ground mount systems

- Based on 2016 system costs

- Created a simplified LCOE calculator to use for "apples-toapples", technology-based comparisons

- Applied this modeling to:

- Evaluate and validate program goals

- Compare \& contrast different module design aspects

- Set cost and performance targets for specific module types in residential, commercial, and utility-scale markets

- Assess different aspects of MOSAIC awardees designs and their potential competitiveness against incumbent technology 


\section{Harvest Efficiency}
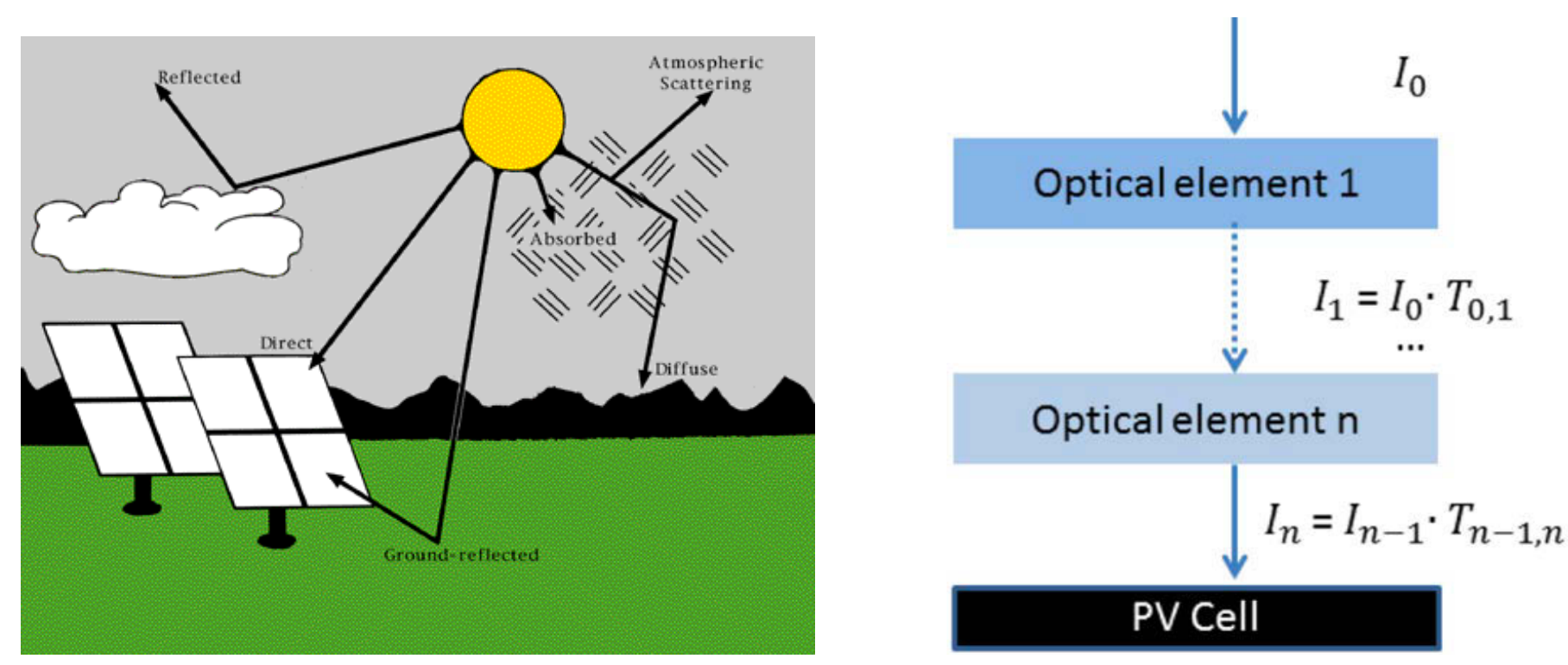

$$
\begin{gathered}
\eta_{H a r v e s t, D C}=f_{D N I} \cdot g(\theta, \phi)_{D N I} \cdot \eta_{o p t, D N I} \cdot \eta_{P V, D N I} \cdot F_{D N I}+ \\
\left(1-f_{D N I}\right) \cdot g(\theta, \phi)_{D I F F} \cdot \eta_{o p t, D I F F} \cdot \eta_{P V, D I F F} \cdot F_{D I F F}
\end{gathered}
$$

- Currently, HCPV systems are rated using only direct normal irradiance (DNI) according to the IEC 62670-1 standard

- MOSAIC efficiency metric is harvest efficiency, which is based on total input irradiance 
Potential Competiveness of Internally-Tracked MOSAIC Systems in Different Markets
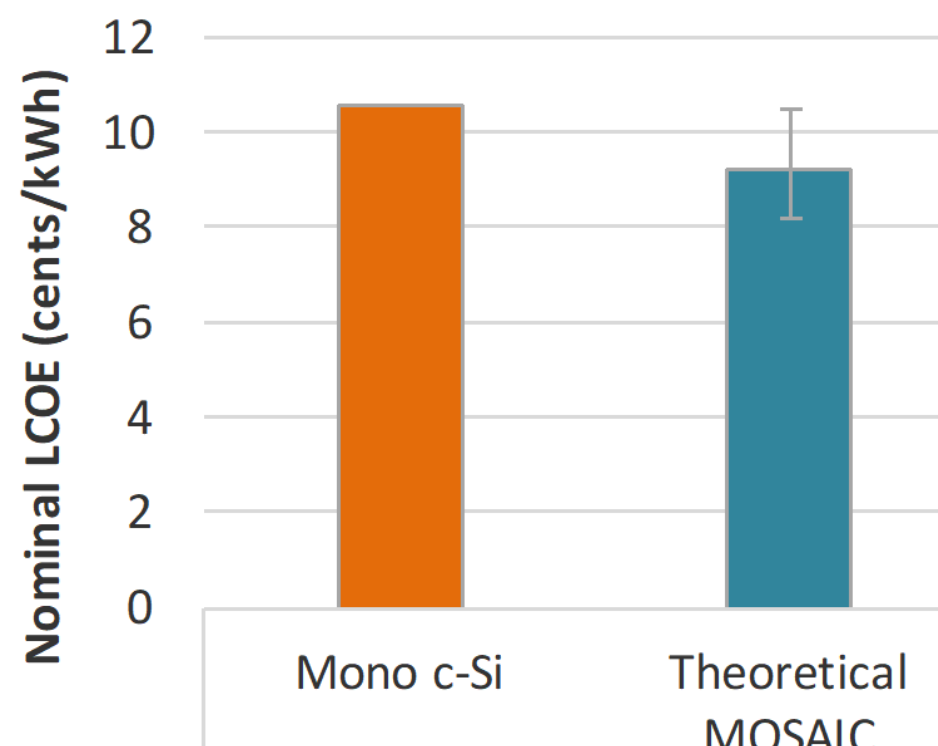

Residential Rooftop

Error bars on MOSAIC represent some possible high and low energy yield scenarios

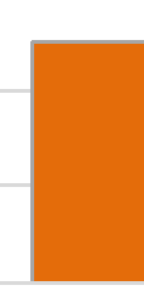

Mono c-Si

Utility-Scale Fixed-Tilt GroundMount
Theoretical MOSAIC System Aligns with MOSAIC Targets:

- Harvest efficiency: $\geq 30 \%$ ( $30 \%$ of total insolation)

- Module production cost: $\$ 0.41 / \mathrm{W}$ $\$ 0.58 / \mathrm{W}$ (\$0.50/W)

- Degradation rate: $<1 \% /$ year $(1 \% /$ year $)$

- Advantage of MOSAIC systems: ability to reach higher efficiencies and potentially have higher energy yields

- Final energy yield that will be realized by MOSAIC systems is currently uncertain

- Residential rooftop systems have higher balance-of-system (BOS) costs, and so the advantage of higher efficiency is greater than for utility-scale

- Advantage of MOSAIC systems will depend on the BOS cost structure at the time of commercialization 


\section{Effects of Module Efficiency and Price}

- LCOE competitiveness depends on many factors

- Two primary drivers are module efficiency and price

- The potential for increased energy density associated with MOSAIC systems can provide additional value in space-constrained applications

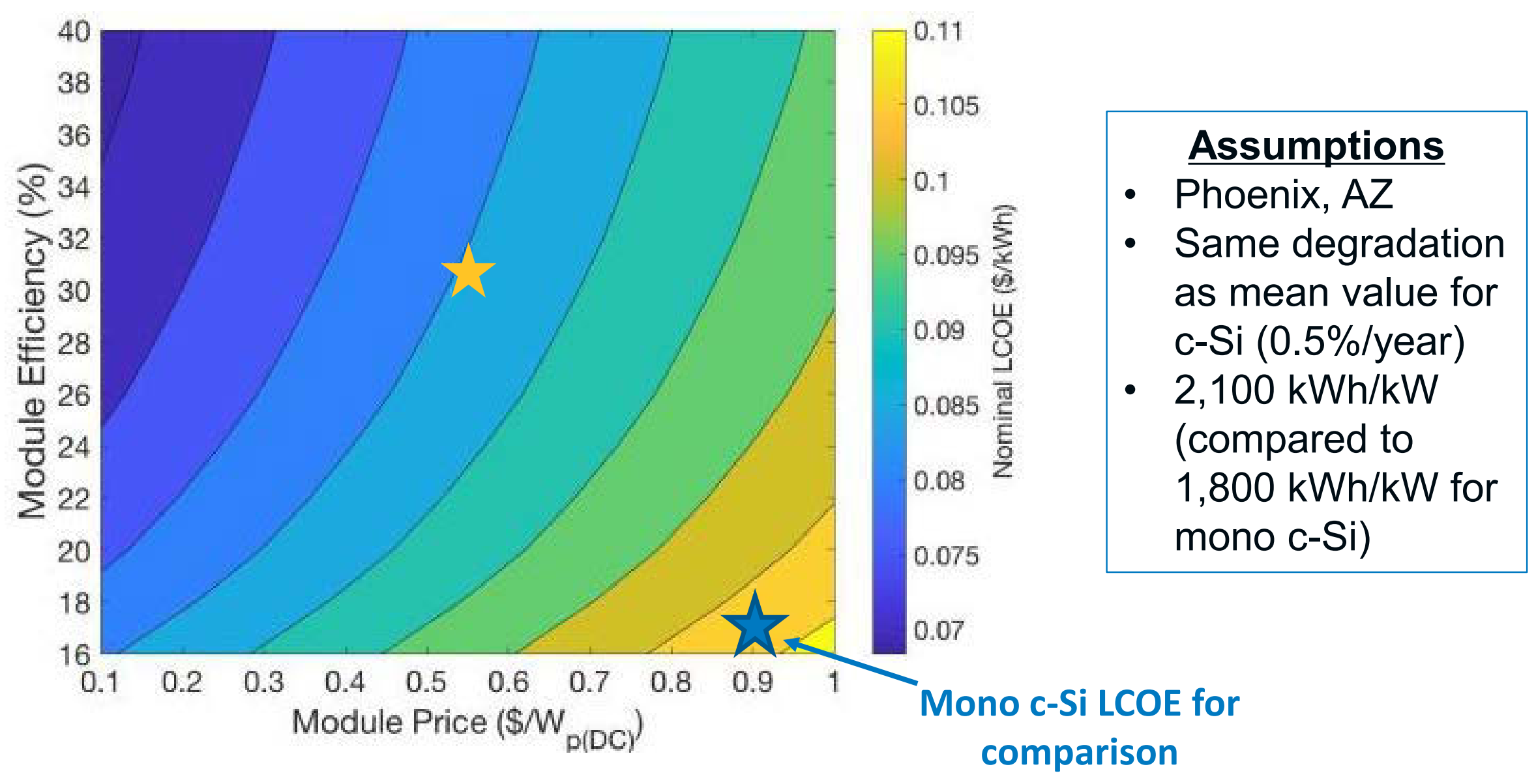




\section{Modeled Two-Axis Tracker Costs in Phoenix, AZ}

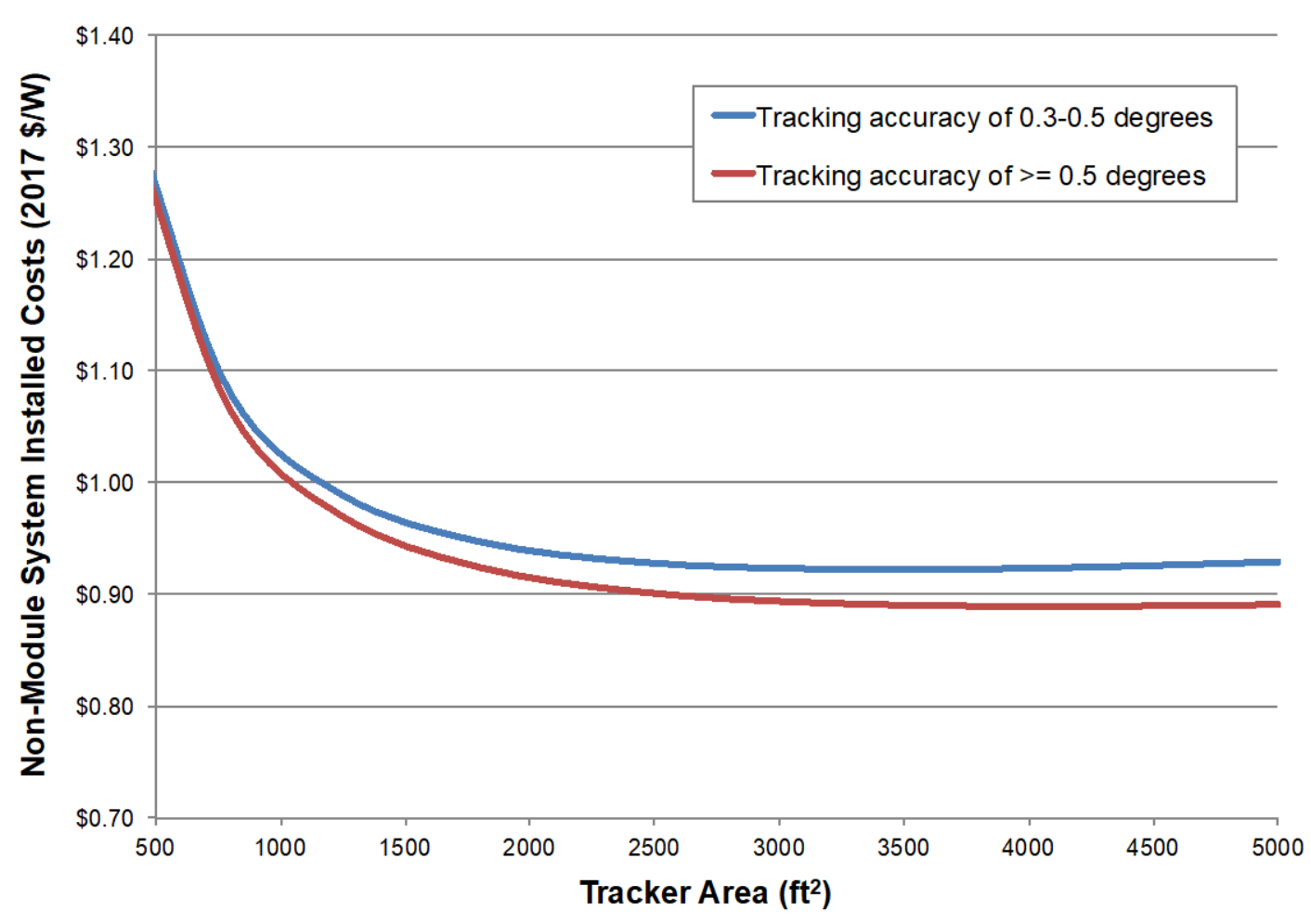

Curve varies depending on dimensions of tracker array, the size of the modules, and the location of installation

- Trackers with accuracies less than $0.5^{\circ}$ are designed for stow conditions $\rightarrow$ little cost change

- For accuracies better than $0.3^{\circ}$, you may require additional structural reinforcement, incurring additional costs, specific to each module/system design

- Trade-offs for increasing tracker area

- Wind and snow loading increases, driving up cost per tracker to maintain accuracy (higher increase with more stringent tracking requirements)

- Watts per tracker increases, driving down overall installed cost per watt 


\section{Two-Axis MOSAIC versus Single-Axis Flat Plate System at Utility-Scale}

- $80 \%$ of utility-scale installations in the US in 2016 used 1-axis tracking

- Higher energy yield requirements for MOSAIC because of increased cost associated with the dual-axis tracker, even with relaxed accuracy requirements

- 2-axis trackers are earlier in the learning curve than 1-axis trackers

Comparison of System Characteristics to Achieve 5.2c/kWh in Kansas City, MO

\begin{tabular}{|c|c|c|c|c|c|}
\hline Technology & $\begin{array}{l}\text { Module } \\
\text { Efficiency }\end{array}$ & $\begin{array}{l}\text { Module } \\
\text { Price }\end{array}$ & $\begin{array}{l}\text { Total Installed } \\
\text { System Price }\end{array}$ & $\begin{array}{l}\text { Degradation } \\
\text { rate }\end{array}$ & $\begin{array}{l}\text { Energy Yield to hit } \\
5.2 \mathrm{c} / \mathrm{kWh} \mathrm{LCOE}\end{array}$ \\
\hline $\begin{array}{l}\text { Current } \mathrm{CdTe}, 1 \text {-axis } \\
\text { tracking }\end{array}$ & $16 \%$ & $\$ 0.39 / W_{p}$ & $\$ 1.20 / \mathrm{W}$ & $0.4 \% /$ year & $\begin{array}{l}1,966 \mathrm{kWh} / \mathrm{kW}_{\mathrm{p}} \\
\text { (modeled energy yield } \\
\text { for CdTe system) }\end{array}$ \\
\hline $\begin{array}{c}\text { Theoretical MOSAIC, } \\
\text { 2-axis tracking: meets } \\
\text { program targets }\end{array}$ & $30 \%$ & $\$ 0.50 / W_{p}$ & $\$ 1.46 / \mathrm{W}$ & $1 \% /$ year & $\begin{array}{c}2,438 \mathrm{kWh} / \mathrm{kW}_{\mathrm{p}} \\
\text { (required to hit } \\
5.2 \mathrm{c} / \mathrm{kWh} \text { ) }\end{array}$ \\
\hline $\begin{array}{c}\text { Theoretical MOSAIC, } \\
\text { 2-axis tracking: } \\
\text { exceeds program } \\
\text { targets }\end{array}$ & $40 \%$ & $\$ 0.20 / W_{p}$ & $\$ 1.04 / W$ & $0.4 \% /$ year & $\begin{array}{c}1,829 \mathrm{kWh} / \mathrm{kW}_{\mathrm{p}} \\
\text { (required to hit } \\
5.2 \mathrm{c} / \mathrm{kWh} \text { ) }\end{array}$ \\
\hline
\end{tabular}




\section{Planar micro-tracking LCOE modeling at Penn State}

\section{Technology Summary}

- Fixed-tilt CPV panels, 300x concentration

- $\mu$-scale $3 \mathrm{~J}$ solar cells, $\sim 42 \%$ efficient

- panel efficiency $35 \%$ of DNI

\section{Annual energy generation}

- Based on PV Watts TMY data \& NREL SPA

- Comparison with 19\% Si panel

- Metric: annual kWh/kWp(dc)

\begin{tabular}{|c|c|c|}
\hline & $\mathbf{1 9} \% \mathbf{S i}$ & $\mathbf{3 5} \% \mathbf{C P V}$ \\
\hline AZ & 1830 & 1610 \\
\hline MO & 1450 & 1160 \\
\hline NY & 1350 & 1070 \\
\hline
\end{tabular}

\section{Conclusions}

- CPV wins on install cost, Si wins on LCOE

- Key difference is $30 \mathrm{yr}$ degradation rate - $0.4 \% / y r$ Si vs. $1 \% / y r$ CPV assumed

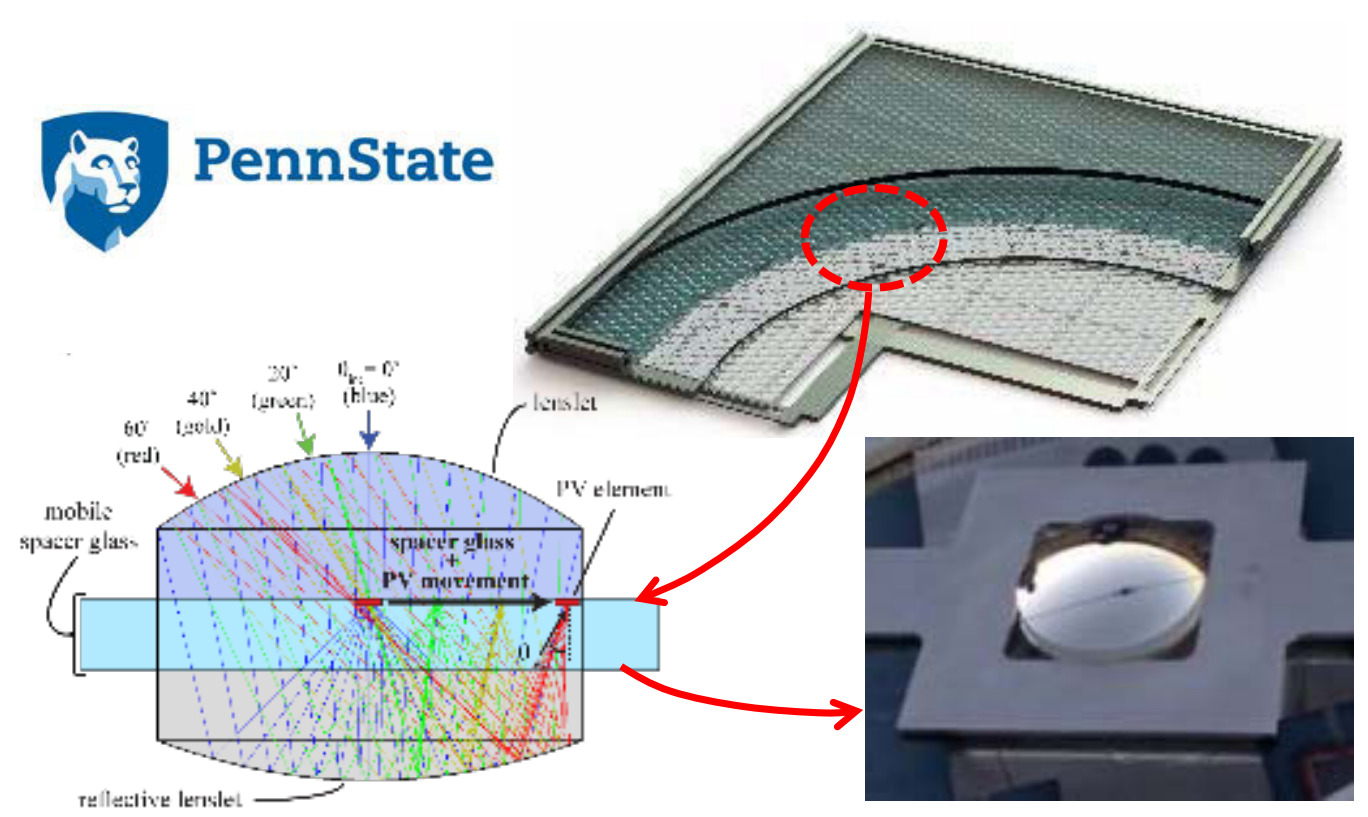

Residential LCOE \& installation cost comparison
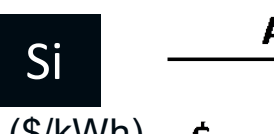

$\operatorname{LCOE}(\$ / \mathrm{kWh})$ Install $(\$ / W p)$

$\begin{array}{rr}\$ & 0.063 \\ \$ & 2.67\end{array}$

\begin{tabular}{lr}
\multicolumn{2}{c}{ MO } \\
\hline & \\
$\$$ & 0.080 \\
$\$$ & 2.66
\end{tabular}

$$
\$ \quad 0.100
$$$$
\$ \quad 2.33
$$$$
\begin{array}{lr}
\$ & 0.113 \\
\$ & 2.50
\end{array}
$$ 


\section{Summary and Conclusions}

- A bottom-up model created from NREL for MOSAIC is being used by awardees to assess their specific systems/designs

- MOSAIC systems could become cost-competitive with other PV technology, particularly in space-constrained applications

- Residential and commercial BOS savings

- We presented an example of this for a residential application and utility-scale application with Penn State's design

- However, this will depend on the specifics of the system, including:

- Manufacturing cost per watt

- Energy yield/harvest efficiency

- System degradation

- Lower tracking accuracy requirements translate to lower tracker costs, to a point

- The modeled premium for two-axis trackers means high performance is required for CPV systems to break-even with existing technology on single-axis trackers in utility-scale markets 


\section{Simplified LCOE equation}

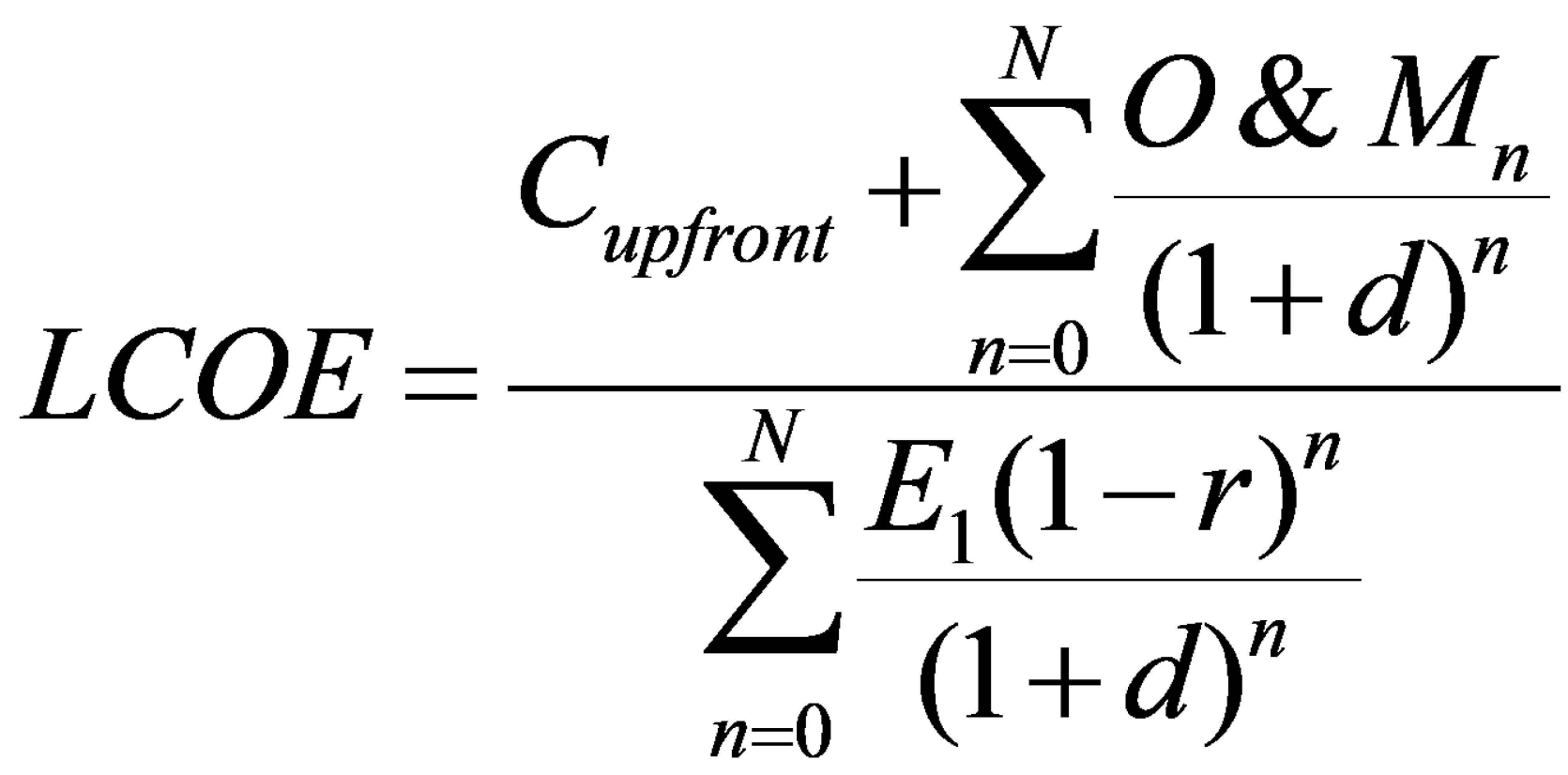




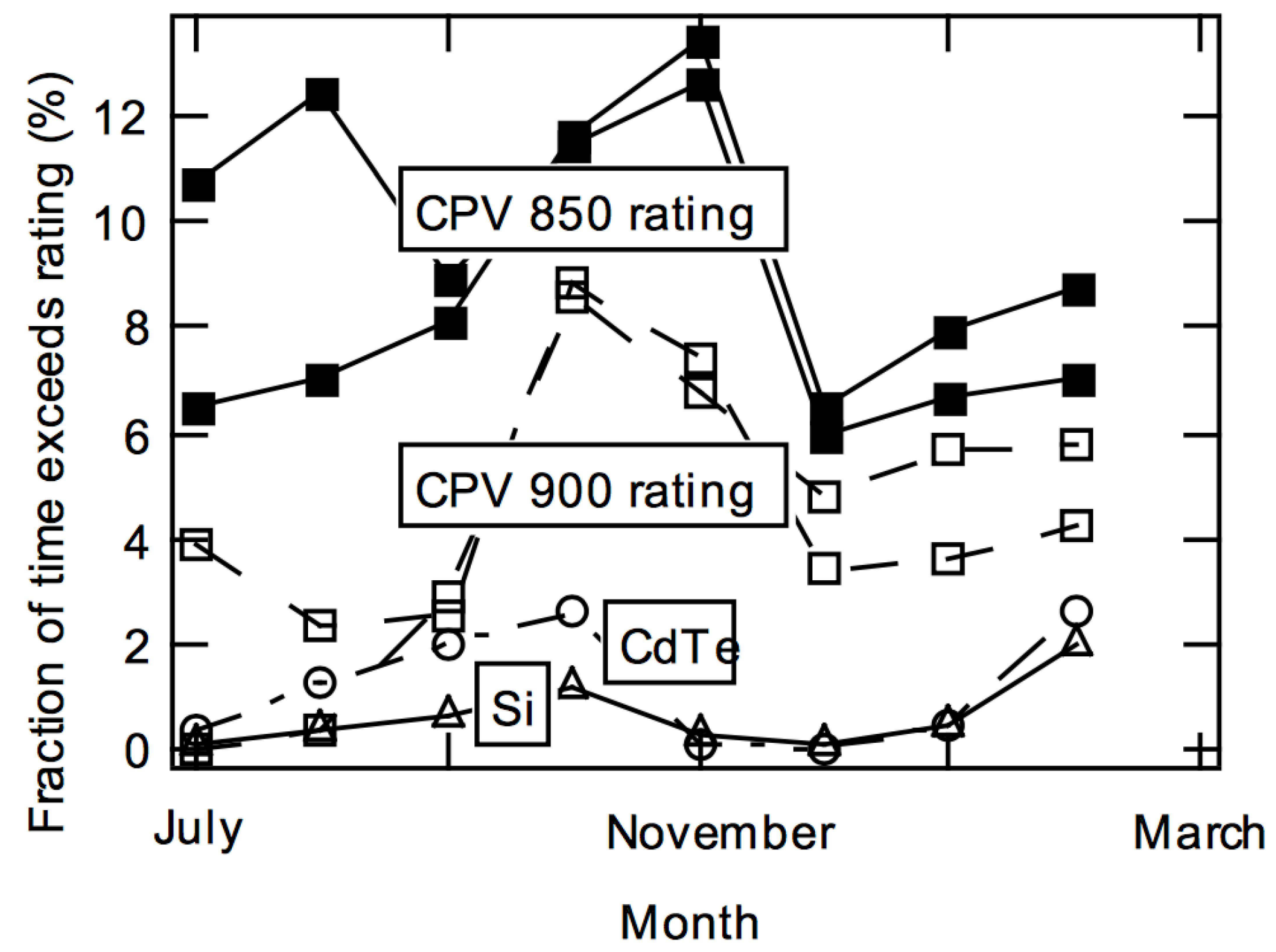




\section{System Cost Model for MOSAIC}

- The dual-axis tracked system cost model assumes a traditional pedestal architecture

- $\quad$ Fixed-tilt and 1-axis tracking architectures identical to those currently used for flat-plate designs

- Users input their specific module characteristics and get out system price and LCOE

- Can compare LCOE to existing technology in 3 locations: Phoenix, Kansas City, New York

- Simplified LCOE model and default financial inputs for easy use by scientific researchers and early-stage projects

User Inputs

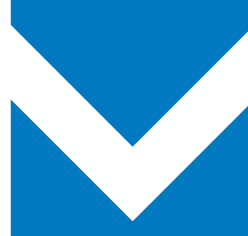

Intermediate

Values

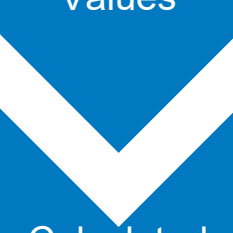

Calculated

Engineering

Parameters

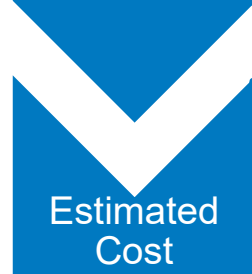

Parameters

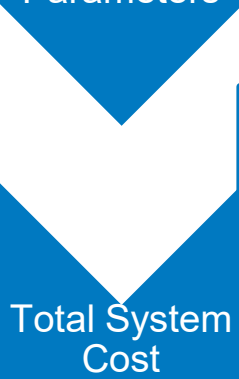

Categories
- Module Characteristics

- System Configurations

- Location

- Financial Parameters

- Wind Speed

- Snow Loading

- Column Type

- Soil Condition

- Foundation Depth

- Racking Component Quantity

- Two-axis Tracking Gear Drive Capacity

- Foundation Cost

- Racking Cost

- Installation Labor Rate

- Two-axis Tracking Gear Drive Cost

- Module Cost

- Tracker Cost

- Structural and Electrical BOS

- Installation Labor Cost

- Permitting and Interconnection

- Sales Tax

- EPC/Developer Overheads 


\section{System Cost Model for MOSAIC}

\section{CORE COST DRIVERS \\ MODEL COST \\ CATEGORIES}

INPUTS

OUTPUTS

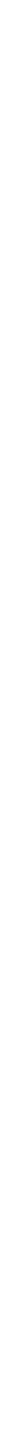

